\title{
World Protected Areas Management, Wildlife Migration and COVID-19 Outbreak: Developing a World Health Care Approach
}

\author{
Saba Kalantary ${ }^{1}$, Ali Jahani ${ }^{2}$, and Reza Jahani ${ }^{3}$ \\ ${ }^{1}$ Tehran University of Medical Sciences \\ ${ }^{2}$ College of Environment \\ ${ }^{3}$ Shahid Beheshti University of Medical Sciences
}

May 26, 2020

\begin{abstract}
Emerging or re-emerging zoonotic diseases are the main issue in global health and affect the well-being of nations. COVVID-19 originated from a wet market where wild animals are sold and rapidly outbreak across worldwide. Analysis outlined bats are key host, so COVID-19 is a zoonotic disease and crossed from animals into humans. Wildlife migration among world protected areas and disease transmission has caused an increased risk of emerging or re-emerging of zoonotic diseases such as COVID-19. Transboundary animal diseases (TDAs) make the health approach more crucial as these diseases cause many problems. Hence, the prevention and control of zoonotic diseases are critical. In this paper, we addressed world protect areas management, wildlife migration, and preventive and control measures aspects on zoonotic diseases such as COVID-19 that have already been globally recommended. South American and African countries due to higher coverage of protected areas in human development regions; and Asian and South American countries due to lack of protected area management assessment are more prone to transmit COVID-19 by wildlife migrations. World Health Organization should pay attention to the determined countries for more practical health care plans in protected area communities and settlement especially in facing with wildlife species.
\end{abstract}

\section{Title page}

World Protected Areas Management, Wildlife Migration and COVID-19 Outbreak: Developing a World Health Care Approach

\section{Running title: Wildlife Migration and COVID-19 Outbreak}

Saba Kalantary ${ }^{1}$, Ali Jahani ${ }^{2 *}$, Reza Jahani ${ }^{3}$

${ }^{1}$ Department of Occupational Health Engineering, School of Public Health, Tehran University of Medical Sciences, Tehran, Iran

${ }^{2}$ Department of Natural Environment and Biodiversity, Faculty of Environment, College of Environment, Karaj, Iran.

${ }^{3}$ Department of Toxicology and Pharmacology, School of Pharmacy, Shahid Beheshti University of Medical Sciences, Tehran, Iran

Corresponding author's E-mail: ajahani@ut.ac.ir, Phone number: 0098-026-32803027 Fax: 0098- 02632807445

\section{Summary}

Emerging or re-emerging zoonotic diseases are the main issue in global health and affect the well-being of nations. COVVID-19 originated from a wet market where wild animals are sold and rapidly outbreak 
across worldwide. Analysis outlined bats are key host, so COVID-19 is a zoonotic disease and crossed from animals into humans. Wildlife migration among world protected areas and disease transmission has caused an increased risk of emerging or re-emerging of zoonotic diseases such as COVID-19. Transboundary animal diseases (TDAs) make the health approach more crucial as these diseases cause many problems. Hence, the prevention and control of zoonotic diseases are critical. In this paper, we addressed world protect areas management, wildlife migration, and preventive and control measures aspects on zoonotic diseases such as COVID-19 that have already been globally recommended. South American and African countries due to higher coverage of protected areas in human development regions; and Asian and South American countries due to lack of protected area management assessment are more prone to transmit COVID-19 by wildlife migrations. World Health Organization should pay attention to the determined countries for more practical health care plans in protected area communities and settlement especially in facing with wildlife species.

Keyword : COVID-19, protected area, Health, Wildlife migration, Zoonotic disease

\section{Introduction}

The novel coronavirus (COVID-19) outbreak began in Wuhan, China, at the end of 2019. COVID-19 continues to spread across the worldwide (Adams \& Walls, 2020). At the time of writing, the number of confirmed cases has now passed 2,700,000, and 190,871 confirmed death reported form the coronavirus (World Health Organization, 2020). The first cases were identified in the wholesale seafood market. There are some restaurants in this market which are popular for serving the type of wildlife for human consumption (Hui et al., 2020). This seafood market is a wet-market which sells wild animals such as bats, snakes, poultry etc. Evidence has indeed shown these wet-markets act as a hotspot for human-animal engagements and zoonotic viruses are able to jump the species barrier leads to the emergence of new zoonotic pathogens (Malik et al., 2020). Different parameters such as expansion trade, travel, and ecotourism, growth of human population, change lifestyle, climate change, rapidly growth pathogens, change in agricultural practices such sc domestication of species of wild animals and intensive integrated animal farming, natural environmental damage, ecological disasters, nutritional and cultural factors etc. have a profound impact upon ignite and extension of new or emergent zoonosis and threat human health (Ellwanger et al., 2018; Plowright et al., 2017; Iturriza-Gomara \& O'Brien, 2016) Zoonotic diseases have changed the life of human during centuries such as Ebola, Zika, severe acute respiratory syndrome (SARS-CoV), Middle East respiratory syndrome coronavirus (MERS-CoV) (Rodriguez-Morales et al., 2020). Coronaviruses have led to three pandemic state, i.e. SARS, MERS, and COVID-19 in the last twenty years (Zhou et al., 2020). COVID-19 disease is the third of instance transmission from species barrier twice from wildlife to human (Bonilla-Aldana et al., 2020). In SARS and MERS cases wild animals such as bats were as host of the coronaviruses that spilt to humans through intermediate hosts including camels and civets. About COVID-19 current data suggest that bats are the most probable initial source of SARS-CoV-2 outbreak (Zhou et al., 2020; Chan et al. 2020). Coronaviruses such as alpha, beta, gamma, and delta coronaviruses circulate in nature amongst diverse wildlife species and can infect mammals and birds, then maybe transmitted to human (Zhou et al., 2020). Thus animal health, human health, and environmental health are linked together (Bonilla-Aldana et al., 2020). Zoonotic diseases are a good example of this relation. Therefore, it's critical from the health approach which understands the transmission cycles; seek mechanisms of prevention, control and decrease of transmission, studies interaction of human with wildlife, diseases in the environment, and diseases ecology (Ahmad et al., 2020). Furthermore, it may be useful for the future outbreak with emerging zoonotic diseases such as COVID-19 and provide effective control to eliminate emerging many probable zoonosis.

\section{Wildlife Migration among World Protected Areas}

Wildlife migrates across the globe, which could be a major factor in the spread of the COVID-19. Wildlife migration takes place at short and high distances, both individually and socially, and on a seasonal basis (Dingle \& Drake, 2017). For example, avian influenza (H5N1) viruses are due to transmitted between migratory/wild birds and may cause a threat human health (Ahmed et al., 2020; Dhama et al. 2012; Sakoda et al., 2012). Migration distance and population are dependent on several factors such as animal species, ecological niches, suitable habitats, and so on. Therefore, it is not possible to control, manage or prevent 
wildlife migration. As we enter the summer season, many animals will migrate from hot regions to cold ones in recent months, bringing a new wave of COVID-19 transmission. Many species of wildlife, including birds, mammals, and fishes, also exhibit migratory behaviors, and many are prone to transmitting the COVID-19. On the other hand, this species lives in a variety of habitats, including terrestrial and aquatic habitats, and nowhere in the world will be safe from the risk of COVID-19 transmitting by wildlife migration. However, it is important to note that wildlife migration is occurred between protected areas where is the most important habitat for animals (Rezazadeh et al., 2019; Shirani et al., 2017, Sobhani et al. 2018). More than 238,563 regions have been designated as a protected area by the International Union of Conservation Nature (IUCN) since July 2018 (Figure 1). Most protected areas are terrestrial and cover over 20 million $\mathrm{km}^{2}$ or $14.9 \%$ of the earth. On the other hand, marine protected areas are fewer in number but cover more than 6 million $\mathrm{km}^{2}$ equivalents to $7.3 \%$ of the oceans (UN Environment Programme World Conservation Monitoring Centre \& International Union of Conservation Nature, 2018).

Therefore, managing and controlling protected areas around the world can be a great help in controlling the spread of the COVID-19. There is also a higher risk of transmitting COVID-19 to countries with higher levels of protected areas (Fig2).

There is good evidence that quarantine in different areas that are infected by COVID-19 will lead to control of virus transmission. The protected areas are potentially prone to the transmission of the virus from animal to human. Therefore these areas should be quarantined or fully observed for COVID-19 infection. Unfortunately, only 21,743 protected areas have an effective management report, (20\% of protected areas in the World Department of Protected Area (WDPA) (UN Environment Programme World Conservation Monitoring Centre \& International Union of Conservation Nature , 2018). This issue limits monitoring and controlling the spread of the COVID-19 in protected areas which is extremely worrying. In the past 10 years, Global Database on Protected Areas Management Effectiveness (GD-PAME) collected data from management effectiveness in 169 countries containing 21,743 different protected areas (UN Environment Programme World Conservation Monitoring Centre \& International Union of Conservation Nature, 2018b). However, in figure 3, we see that most protected areas in the world have not been assessed for management effectiveness and this make so hard to manage the COVID-19 infection in these areas. The highest number of fully managed protected areas is found in Europe, where protected areas having been repeatedly assessed (Figure 4). Hence, the control of COVID-19 infection in between wild animals and human is more probable in Europe than other regions. More than $82 \%$ of protected areas in the world are managed by government organizations (UN Environment Programme World Conservation Monitoring Centre \& International Union of Conservation Nature, 2018). hence governments are the first responsible for COVID-19 infection control in wildlife migratory behaviors in protected areas. Compared to other geographical regions, this ratio has the highest rate in Europe and therefore, EU governments are most responsible for controlling the COVID-19 in these areas.

Connectivity between protected areas is other indicator of COVID-19 transmission. Connectivity of protected area means that wildlife is easily relocated or migrated between these areas, and it is essential to maintain the viability of species, communities and ecosystems (Sadegh oghli et al.,

2019a,b; Haghverdi et al., 2019a,b).. Figure 5 reveals that African countries have the most connected protected areas. It means that wildlife easily can transmit COVID-19 between countries on this continent. The transmission of COVID-19 between animal and human will be facilitated. On the other hand, some regions are wild with low human populations and some regions are occupied by human settlements or human activities (such as farming and energy production); and protected areas are scattered among them. National Geographic Society (NGS) developed a human impact map developing to illustrate the planet's relatively untouched terrestrial landscapes (Fig 6) (UN Environment Programme World Conservation Monitoring Centre \& International Union of Conservation Nature, 2018a). Indeed protected areas in not wild regions are more prone to outbreak COVID-19 between animals and human. 


\section{The transboundary animal diseases and One Health}

The "One Health" is a concept that introduces that mankind health is closely interdependent with animal health and environmental health. This concept is defined by the World Organization for Animal Health (OIE) (World Organisation foe Animal Health, 2020). This approach facilitates control and prevention of emerging zoonotic diseases. Transboundary animal diseases (TADs) defined those that can spread very rapidly through of animals, irrespective of national boards and lead to serious socio-economic harm and possibly public health (Torres-Velez et al. 2019). TADs circulate widely in worldwide. In general, TADs predominantly are in low-countries or with less than optimal biosafety, particularly in South Asian countries, although no country is immune from the risk of TADs. These countries recognized as a global hotspot for emergence or reemergence of infectious diseases of animal source such as COVID-19. On the other hand, protected areas are surrounded by human developed area in these countries (Fig 6) which makes these areas more prone for COVID-19 virus transmission between human and wild animals. Improvement of human health, animal health, and environmental health by One Health approach to the control of emerging zoonotic disease at the national, regional and global level is worth with the increasing emergence of infectious diseases. Thus, the human and animal health professionals should comprehensive perception about the concept of One Health, understand the complexities of the spread of zoonotic disease between human and animals, and use the One Health approach in their clinical actions. Collaboration and communication between human health and wildlife professionals can result in human and animal health that can be identified by practicing One Health (Dhama et al. 2013). Practicing One Health is critical in the identification and prevention of diseases relevant to occupational health hazards (Dhama et al. 2013). The main percent of COVID-19 patients associate with occupational exposure, such as persons who worked in the wet market or protected area rangers. International Labour Organization (ILO) has introduced COVID-19 as a first new occupational disease in this decade (International Labour Organization , 2020). Implementation of One Health approach needs to collaborative efforts of veterinary and human medicine, environmental, wildlife and public health (Osburn et al., 2009). The collaborate of international organizations like World Organization for Animal Health (WOAH), Food and Agricultural Organization (FAO), and World Health Organization (WHO) suggest for the disease management measures (United Nations, 2008).

\section{Prevention and control of zoonotic diseases}

The interaction of human with wild animals can lead to varied emerging or re-emerging global zoonotic pandemic such as SARS as well as MERS (Day, 2011). Some of the comprehensive approaches require for the update to prevent zoonotic diseases and to conserve integrity of ecosystem and environment is summarized as follows:

- Understanding the relation between human and wildlife and Judicious utilization of land and water ((Jahani et al., 2020; Barati et al., 2017).

- Wildlife health science is critical for universal diseases management and needs to pay attention especially in South American and African countries having the highest coverage of protected areas

- Establishing approaches towards the management of emerging and re-emerging diseases accounting for the complicated interconnections among species;

- Biodiversity protection outlook;

- Wild animal populations generate a significant and instant threat to humans and at the same time to food security and need to multidisciplinary efforts and scientific concerns for restrict culling of wild species;

- Protected areas settlements management and Human community training in hygienic affairs in facing with wildlife to control COVID-19 outbreak.

- Protected areas quarantine for tourism, hunting, researches or other human activities; and wildlife observation for COVID-19 symptoms. Ii is crucial specially in Asian, Pacific and African countries that protected areas are surrounded by human developed areas.

Increased investment in the global human and animal health infrastructure (one health) and protected area assessment plans, especially in South American and Asian countries with low percentage of assessed protected 
areas for management effectiveness (Dhama et al. 2013).

Furthermore, some of the routes for control zoonotic diseases outbreak is given below:

management practice and biosafety is without, a doubt, are the best way (Hafez, 2005). Another way to control zoonotic diseases would be via the use of vaccination in protected areas local communities, but there is some obstacle such as variability in the strains, difficulty in production, cost constraints, prohibitively expensiveness etc. On the other hand, in animal vaccination, there are basic biological differences that effect on vaccination protocols, between each species and different species (Paul-Pierre, 2009; Dhama et al. 2012a). Moreover, regulations governing registration and marketing of vaccines for wild animals should be flexible and development of science and technology also the new vaccines available needs to be considered for animal disease control recommendations (Moran et al., 2009; Gargano et al. 2013). The drug delivery systems such as nanoparticles, liposoma, the viral vector should be investigated and used to achieve efficient and protective immune responses ((Dhama et al. 2013; Babiuk et al., 2003; Suri et al., 2007). Furthermore, nutrition and nutritional status can have a direct and indirect impact upon the augment immune defenses (Dhama et al. 2013; Mahima et al., 2013).

\section{Conclusion}

The main question is, how are we planning to counter the next zoonotic diseases epidemic or pandemic that is likely to occur within the next years? We should learn from the novel coronavirus pandemic outbreak in Wuhan, China. WHO has now increased the risk assessment of this emerging COVID-19 to a very highrisk category. Researchers and health agencies across the worldwide are putting efforts to stop spread of novel coronavirus by prevention and control measures. Human, animal, and environmental health is very important and they are linked together.

Therefore, practical management of world protected areas, wildlife migration routes observation, animal species monitoring for symptoms of COVID-19, and biosafety, controlling zoonotic diseases in animal reservoirs, understanding of the relations between human and wildlife, international health regulations for high risk countries with higher coverage of protected areas and lower management effectiveness assessment; the strengthening of global wildlife health systems; and the One Health concept should be considered for COVID19 neutralizing.

\section{Funding}

None declare.

\section{Acknowledgements}

The authors would like to acknowledge the Tehran University of Medical Sciences and the College of Environment.

\section{Ethical Statement}

The authors confirm that the ethical policies of the journal, as noted on the journal's author guidelines page, have been adhered to. No ethical approval was required as this article because this study did not involve invasive procedures and, did not involve laboratory animals.

\section{Conflict of interest statement}

The author(s) declare no competing interests.

\section{Data availability statement}

The data that support the findings of this study are available from the corresponding author upon reasonable request.

\section{References}


Adams JG, Walls RM. (2020) Supporting the health care workforce during the COVID-19 global epidemic. JAMA. https://doi:10.1001/jama.2020.3972.

Ahmad T, Khan M, Haroon Musa TH, Nasir S, Hui J, Rodriguez-Morales AJ. (2020) COVID-19: Zoonotic aspects. Travel Med. Infect. Dis. 101607.https://doi.org/10.1016/j.tmaid.2020.101607.

Ahmed JS, Sparagano O and Seitzer U.(2010) One Health, One Medicine: Tackling the Challenge of Emerging Diseases. Transbound. Emerg. Dis. 57: 1-2. https://doi.org/ 10.1111/j.1865-1682.2010.01132.x.।

Barati, B., Jahani, A., Zebardast, L., Rayegani, B. (2017) Integration assessment of the protected areas using landscape ecological approach (Case Study: Kolah Ghazy National Park and Wildlife Refuge). The Journal of Town and Country Planning, 9(1): 153-168. https://doi.org/ 10.22059/JTCP.2017.61412.

Bonilla-Aldana DK, Dhama K, Rodriguez-Morales AJ. (2020) Revisiting the one health approach in the context of COVID-19: a look into the ecology of this emerging disease. Adv Anim Vet Sci. 8(3):234-7. https://doi.org/ 10.17582/journal.aavs/2020/8.3.234.237.

Babiuk LA, Gomis S and Hecker R., (2003). Molecular approaches to disease control. Poult. Sci. 82(6): $870-875$.

Chan JF-W, Yuan S, Kok K-H, To KK-W, Chu H, YangJ, et al. (2020) A familial cluster of pneumonia associated withthe 2019 novel coronavirus indicating person-to-person transmission: a study of a family cluster. The Lancet.

Dingle, H.;, V. A, Drake. (2007) "What is migration?". BioScience. 57 (2): 113-121. https://doi.org/10.1641/B570206.

Dhama K, Verma AK, Rajagunalan S, Deb R, Karthik K, Kapoor S, Mahima, Tiwari R, Panwar PK and Chakraborty S. (2012b) Swine flu is back again: A review. Pak. J. Biol. Sci. 15(21): 1001-1009. https://doi.org/10.3923/pjbs.2012.1001.1009.

Day MJ. (2011) One health: the importance of companion animal vector-borne diseases. Parasit. Vectors, 4: 49. https://doi.org/10.1186/1756-3305-4-49.

Dhama K, Wani MY and Tiwari R (2012a) Surveillance/networking, prevention and control strategies for zoonotic avian pathogens in context to one health concept with particular reference to south-asia. Lead Paper Presented in International Symposium on One Health : Way Forward to Challenges in Food Safety and Zoonoses in 21st Century and XIth Annual Conference of Indian Association of Veterinary Public Health Specialists (IAVPHS), Dec. 13-14, 2012 at School of Public Health and Zoonoses, Guru Angad Dev Veterinary and Animal Sciences University, Ludhiana, Punjab, India.

Ellwanger JH, Chies JAB. (2018) Zoonotic spillover and emerging viral diseases - time to intensify zoonoses surveillance in Brazil. Braz. J. Infect. Dis. 22(1): 76-78. https://doi.org/10.1016/j.bjid.2017.11.003.

Gargano LM, Gallagher PF, Barrett M, Howell K, Wolfe C, Woods C and Hughes JM. (2013) Issues in the Development of a Research and Education Framework for One Health. Emerg. Infect. Dis. J. 19(3) https://doi.org/10.3201/eid1903.121103

Hui DS, I Azhar E, Madani TA, Ntoumi F, Kock R, Dar O, Ippolito G, Mchugh TD, Memish ZA, Drosten C, Zumla A, Petersen E. (2020) The continuing 2019-nCoV epidemic threat of novel coronaviruses to global health - The latest 2019 novel coronavirus outbreak in Wuhan, China. Int. J. Infect. Dis. 91:264-266. https://doi.org/10.1016/j.ijid.2020.01.009.

Haghverdi, F., Jahani, A., Zebardast, L., Makhdoom, M., Goshtasb, H. (2019) Integration assessment of Protected Rangeland habitats using landscape ecological approach, Journal of Plant Ecosystem Conservation 7(14): 1-20.

Haghverdi, F., Jahani, A., Zebardast, L., Makhdoom, M., Goshtasb, H. (2019) Quantifying the Fragmentation of the Wildlife Habitat Using Landscape Ecology Approach (Case Study: Lar National Park and Varjin 
Protected Area), Journal of Animal Environment 10(4): 21-32.

Hafez HM. (2005) Governmental regulations and concept behind eradication and control of some important poultry diseases. World Poult. Sci. J. 61: 569-581. https://doi.org/10.1079/WPS200571.

ILO Standards and COVID-19 (coronavirus), [Accessed 27 Mar 2020; cited 17 Apr 2020]. Available from: https://www.ilo.org/global/standards/WCMS_739937/lang-en/index.htm.

Iturriza-Gomara M. (2016) O'Brien SJ. Food borne viral infections.Curr Opin Infect Dis. 29 (5), 495-501.

Jahani, A., Goshtasb, H., Saffariha, M., 2020. Tourism impact assessment modeling in vegetation density of protected areas using data mining techniques, Land Degradation \& Development. https://doi.org/10.1002/ldr.3549.

Osburn B, Scott C and Gibbs P. (2009) One World - One Medicine - One Health: emerging veterinary challenges and opportunities. Rev. Sci. Tech. Off. Int. Epiz. 28(2): 481-486. https://doi.org/10.20506/rst.28.2.1884

One Health [Accessed 27 Mar 2020; cited 20 Apr 2020]. Available from:https://www.oie.int/en/forthemedia/onehealth/.

Malik YS, Sircar S, Bhat S, Sharun K, Dhama K, Dadar M, Tiwari R, Chaicumpa W. (2020) Emerging novel Coronavirus (2019-nCoV)-Current scenario, evolutionary perspective based on genome analysis and recent developments. Vet. Q. 40:68-76. https:// doi.org/10.1080/01652176.2020.172799.

Mahima, Ingle AM, Verma AK, Tiwari R, Karthik K, Chakraborty S, Deb R, Rajagunalan S, Rathore R and Dhama K. (2013) Immunomodulators in day to day life: a review. Pak. J. Biol. Sc. 16 (17): 826-843. tps:// doi.org/ 10.3923/pjbs.2013.826.843

Moran M, Guzman J, Ropars A-L, McDonald A and Jameson N. (2009) Neglected disease research and development: How much are we really spending? PLoS Med. 6: e1000030.

Plowright RK, Parrish CR, McCallum H, Hudson PJ,Ko AI, Graham AL, et al. (2017) Pathways to zoonotic spillover.Nat Rev Microbiol. 15 (8), 502-10. https://doi.org/10.1038/nrmicro.2017.45

Paul-Pierre P. (2009) Emerging diseases, zoonoses and vaccines to control them. Vaccine, 27: 6435-6438. https://doi.org/10.1016/j.vaccine.2009.06.021

Rodriguez-Morales AJ, Bonilla-Aldana DK, Balbin-Ramon GJ, Rabaan AA, Sah R, Paniz-Mondolfi A, Pagliano P, Esposito S. (2020) History is repeating itself: Probable zoonotic spillover as the cause of the 2019 novel Coronavirus Epidemic. Infez Med. 28(1):3-5.

Rezazadeh, S., Jahani, A., Goshtasb, H., Makhdoum Farkhondeh, M. (2019) Evaluation of the ecological capability of Bashgol protected area using zoning approach and assessment of feasibility of its upgrade to higher level of conservation, Journal of animal environment 10(4): 163-172.

Sakoda Y, Ito H and Uchida Y. (2012) Reintroduction of H5N1 highly pathogenic avian influenza virus by migratory water birds, causing poultry outbreaks in the 2010-2011 winter seasons in Japan. J. Gen. Virol. 93(Pt 3): 541-550. https://doi.org/10.1099/vir.0.037572-0

Shirani Sarmazeh, N., Jahani, A., Goshtasb, H., Etemad, V. (2017) Ecological Impacts Assessment of Recreation on Quality of Soil and Vegetation in Protected Areas (Case Study:Qhamishloo National park and Wildlife Refuge), Natural Environment, 70(4): 881-891.

Sobhani, P., Goshtasb, H., Nezami, B., Jahani, A. (2018) Evaluation of Promoting Conservation Hunting Areas (Case Study:Hamedan Alvand No-Hunting Area). Environment sciences and technology, 20(3): 143157. 
Sadegh oghli, R., Jahani, A., Alizadeh Shabani, A., Goshtasb, H. (2019) Quantifying the Fragmentation of Landscape as an Index for the Assessment of the Wildlife Habitat (Case Study: Protected Area of Jajroud), Journal of Animal Environment 11(1): 13-20.

Sadegh oghli, R., Jahani, A., Alizadeh Shabani, A., Goshtasb, H. (2019) Evaluation of Landscape Structure for Development and Integration of the Protected Areas, Town \& Country Planning, 11(1): 57-78.

Saura S., Bertzky B., Bastin L., Battistella L., Mandrici A. and Dubois G. (2018) Protected area connectivity: Shortfalls in global targets and country-level priorities. Biol. Conserv. 219: 53-67. https://doi.org/10.1016/j.biocon.2017.12.020.

Suri SS, Fenniri H and Singh B. (2007) Nanotechnology-based drug delivery systems. J. Occupational Med. Toxicol. 2: 16. https://doi.org/10.1186/1745-6673-2-16.

Torres-Velez F, Havas KA, Spiegel K, Brown C. (2019) Transboundary Animal Diseases as Re-Emerging Threats-Impact on One Health. InSeminars in diagnostic pathology. WB Saunders.

UNEP-WCMC, IUCN and NGS (2018). Protected Planet Report 2018. UNEP-WCMC, IUCN and NGS: Cambridge UK; Gland, Switzerland; and Washington, D.C., USA.

UNEP-WCMC and IUCN. (2018a) Protected Planet: The World Database on Protected Areas (WDPA), July 2018 version, Cambridge, UK: UNEP-WCMC and IUCN. Available at: www.protectedplanet.net.

UNEP-WCMC and IUCN. 2018b. Protected Planet: The Global Database on Protected Areas Management Effectiveness (GD-PAME), Cambridge, UK: UNEP-WCMC and IUCN. [Accessed 27 Jul 2018; cited 20 Apr 2020]. Available from: http://www.protectedplanet.net.

United Nations. Contributing to one world, one health: strategic framework for reducing risk of infectious diseases at the animal-human-ecosystem interface. FAO/OIE/WHO/UNICEF/UNSIC/World Bank. [Accessed 7 Mar 2008; cited 19 Apr 2020]. Available from: http://un-influenza.org/files/OWOH_14Oct08.pdf.

World Health Organization (WHO). Coronavirus disease (COVID-19) outbreak situation [Accessed 25 Mar 2020; cited 26 Apr 2020]. Available from: https://www.who.int/emergencies/diseases/novel-coronavirus2019 .

Zhou P, Yang XL, Wang XG, Hu B, Zhang L, Zhang W, Si HR, Zhu Y, Li B, Huang CL, Chen HD. (2020) Discovery of a novel coronavirus associated with the recent pneumonia outbreak in humans and its potential bat origin. BioRxiv. https://doi.org/10.1101/2020.01.22.914952.

Fig1 . The map of the world's protected areas (UN Environment Programme World Conservation Monitoring Centre \& International Union of Conservation Nature, 2018a)

Fig2. Map of protected areas in different countries in the world based on terrestrial coverage (UN Environment Programme World Conservation Monitoring Centre \& International Union of Conservation Nature , 2018a).

Fig3. Percentage of assessed protected areas for management effectiveness (UN Environment Programme World Conservation Monitoring Centre \& International Union of Conservation Nature , 2018b)

Fig 4 . The number of effective management per region (UN Environment Programme World Conservation Monitoring Centre \& International Union of Conservation Nature , 2018b)

Fig5 . Map of 'Protected Connected land' in the world (Saura et al. 2018)

Fig 6 . Human impact map with protected areas (UN Environment Programme World Conservation Monitoring Centre \& International Union of Conservation Nature, 2018a) 

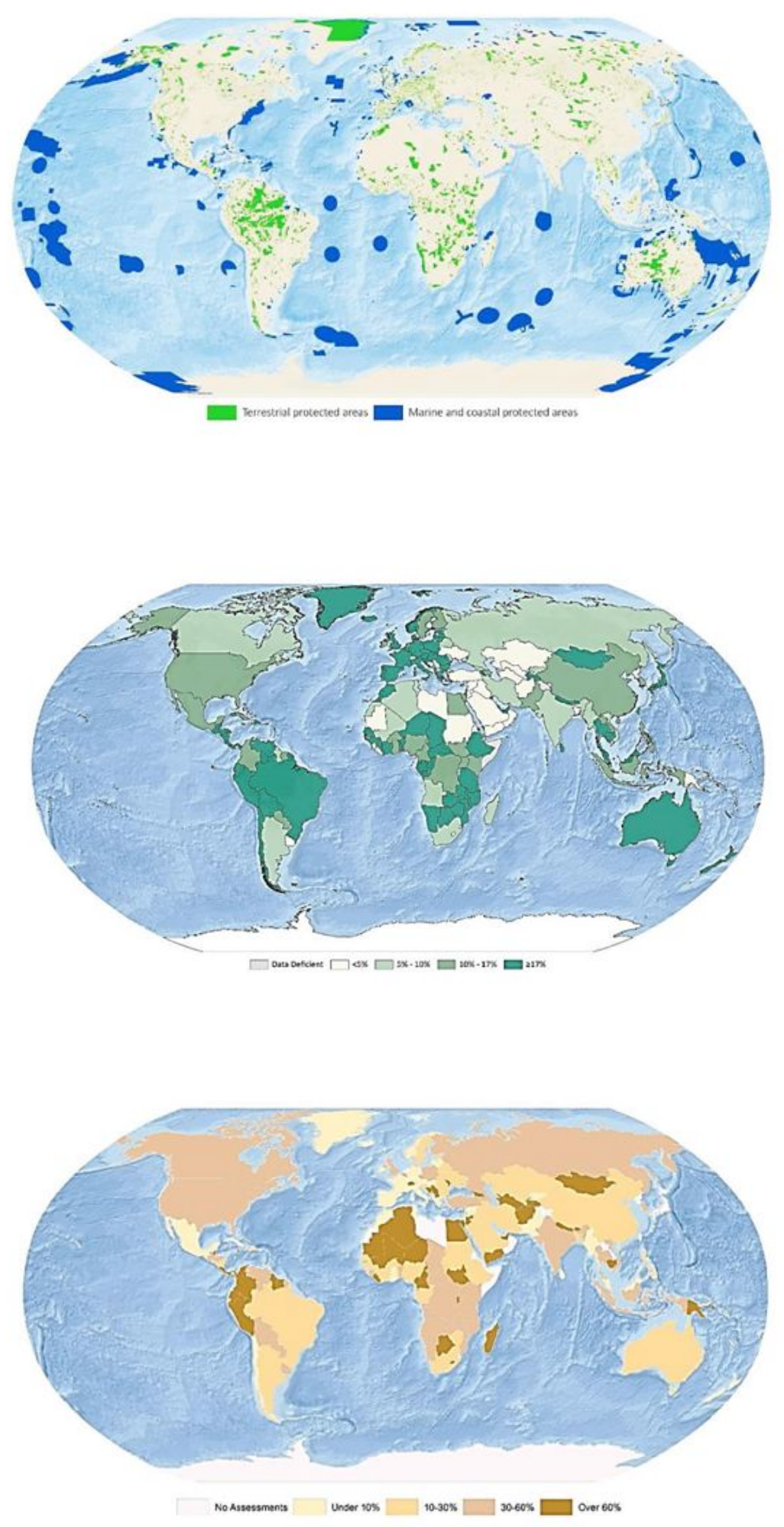

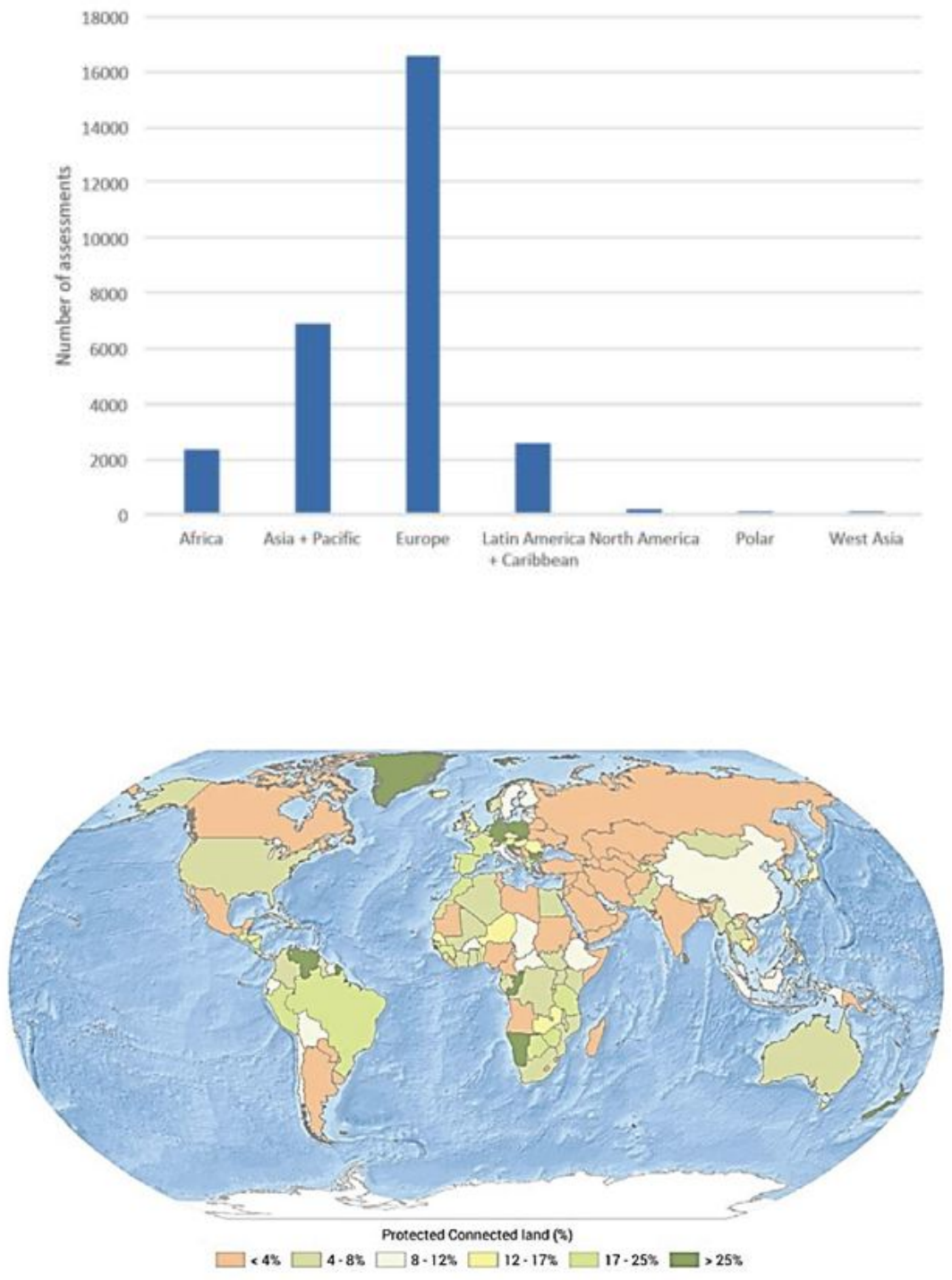


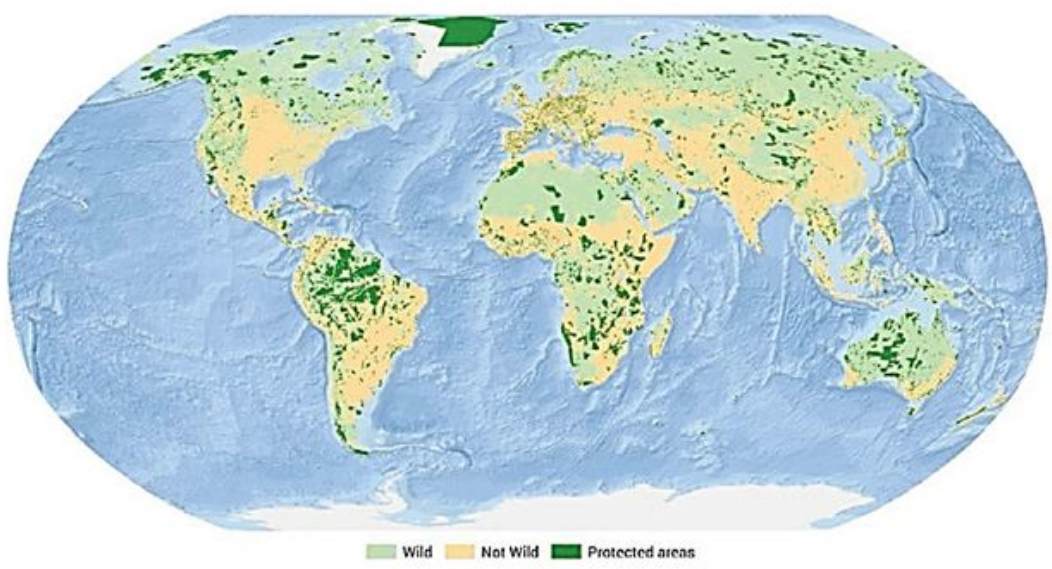

